\title{
Foreign Dissemination Modes of Chinese Culture Based on the Confucius Institute
}

\author{
Yao Hong a, * \\ Chongqing Technology and Business Institute, Chongqing, China \\ ayaoyao-cecily@163.com
}

\begin{abstract}
Keywords: Chinese culture; communication effect; Hungary; the Confucius Institute at the Eotvos Lorand University.
\end{abstract}

\begin{abstract}
In order to explore the effect of Chinese culture on the cultural communication of the Confucius Institute at the Eotvos Lorand University and provide targeted development suggestions for the development of the Confucius Institute at the Eotvos Lorand University on the basis of this research, a combination of quantitative and qualitative research methods was used to study the Confucius Institute at the Eotvos Lorand University, Hungary. The results showed that the Chinese learners of the Confucius Institute at the Eotvos Lorand University have been learning and studying Chinese culture mainly because of internal motivation [1], the need of increasing knowledge and job-hunting, and their overall attitude towards Chinese culture is positive. It also showed that there are significant differences in their perceptions and attitudes towards different Chinese cultural contents. Also, there are differences in the reception of Chinese culture at different levels and their cognition degree and preference of material culture are obviously higher than that of behaviour culture and spiritual culture [2]. Their main channels for receiving Chinese culture are Chinese classes and mass media. Thus, it is necessary for the Confucius Institute at the Eotvos Lorand University to continuously expand the channels of cultural communication.
\end{abstract}

\section{Introduction}

The improvement of China's international competitiveness and overall national strength has made the "Craze for learning Chinese language" continue to heat up. Although the continuous warming of the "Craze for learning Chinese language" has not only improved China's international image but also broadened the channels for foreigners to learn about China, we have to admit that, as a whole, there are still significant differences in the communication effect between different levels of Chinese culture in different countries [3]. The development of the Confucius Institutes in the world also needs further detailed assessment. On the whole, the development of Chinese language still suffers from the problem of "cold abroad and warm at home", so the effect of communication is not satisfactory, and there are problems, such as a shortage of Chinese teaching staff, and Chinese textbooks not meeting the requirements of foreign teaching situations etc. In addition, some western countries are even on the alert to the spread of Chinese culture and regard the spread of Chinese culture at the Confucius Institute as a kind of hegemony [4]. Therefore, how to grasp the boundary between cultural communication and cultural hegemony is what we must pay attention to.

Through reading a lot of literature in the earlier period and studying $\mathrm{Wu}$ Ying project group's method of investigation and research on the sixteen Confucius Institutes in the five countries, the advantages and disadvantages of their research method were discovered. On the basis of Wu Ying group's research, the research scope was expanded at the level of countries, so Hungary, which is not only deeply influenced by the European culture but also has certain oriental cultural characteristics, was chosen as the object of the research in order to evaluate the cultural transmission effect of Chinese culture in Hungary [5]. On this basis, some suggestions and strategies for the future development of Chinese culture communication in the Confucius Institute at Eotvos Lorand University was put forward. 


\section{Investigation Methods}

\subsection{Questionnaire Survey}

The questionnaire survey of this thesis was based on the investigation of the one used in the book Confucius Institute and Chinese Cultural Communication written by Wuying, in which the sixteen Confucius Institutes in the five countries were surveyed [6]. The Questionnaire survey used in this thesis was revised in response to the ethnic characteristics of Hungary in order to investigate the motives of the students learning Chinese in the Confucius Institute at the Eotvos Lorand University in Hungary, their knowledge of and attitudes towards Chinese culture, their acceptance of different aspects of Chinese culture, and their approaches to contact with Chinese culture. Then, the data results were entered and analyzed by using Excel data analysis software, and charts were created so that the results of the questionnaire could be more intuitively reviewed and recommendations could be made.

\subsection{Interviewing Method}

In order to further explore the questions such as the learners' motivation in Chinese learning, their knowledge of and attitudes towards Chinese culture, and their approaches to contact with Chinese culture etc. and detailed reasons as well as the data complement of the questionnaire survey, 10 learners of Chinese language were selected from the elementary level, intermediate level, and senior level respectively. They were interviewed and the content of the interviews were recorded and organized.

\subsection{Respondents}

Hungary has many similarities in history, language, and cultural customs with the ancient Xiongnu people in northwestern China. At present, there is no information on the origin of Hungary, but it can be believed that Hungary is a nation with both eastern and western cultural characteristics. The author taught for one year in Hungary and found that the local people are very close and friendly to the Chinese people. Hungary is also different from the other countries in Europe, and they think that they are unique and their national character is more introverted than that of the typical European countries such as Spain, France, and Italy. There are many similarities in personality traits between the students there and the Asian students [7]. Based on the particularities of Hungarian culture and national character, the author took Hungarian Chinese-language learners as the object of the investigation and studied the communication effect of Chinese culture in Hungary.

\section{The Results of the Survey}

On the whole, the results of the survey are mainly shown in the following aspects: First, the learners of the Confucius Institute at the Eotvos Lorand University were exposed to Chinese culture mainly for practical purposes, and their main motivation of learning Chinese language was to broaden knowledge and get more job opportunities. Secondly, the Chinese-language learners of the Confucius Institute at the Eotvos Lorand University have a positive perception on Chinese culture, and Chinese-language learning is very helpful in enhancing their affection for China. Third, the Chinese-language learners of the Confucius Institute at the Eotvos Lorand University have significant differences in cognition and attitudes towards different cultural content, and they have different levels of acceptance of Chinese culture [8]. In addition, material culture communication is the most effective and also the most popular way among the interviewees. Fourth, the mass media and Chinese language classes are the main channels for the Chinese-language learners of the Confucius Institute at the Eotvos Lorand University to receive Chinese culture, so it is necessary to continuously expand the channels of Chinese culture communication.

\subsection{Sample Structure Analysis}

There are three kinds of courses in the Confucius Institute at the Eotvos Lorand University: interest classes, adult module classes, and single counseling classes. And the number of language learners there is maintained at 110 to 150 . It is necessary to explain that the respondents of the survey are students of the Eotvos Lorand University, not including the students from the Confucius 
Classroom and the major teaching sites affiliated to the Confucius Institute. A total of 105 questionnaires were distributed in this survey, and 95 of them were recovered, with 93 valid questionnaires. Seen from the perspective of gender, the proportion of boys is $46.2 \%$, and the proportion of girls is $53.8 \%$. So, the proportion of girls is slightly higher than that of boys. Then, seen from the perspective of age composition, the youngest is 14 years old while the oldest is 70 years old. The age span is large, with a mean value of 32.17 , a median of 30 years, and an age dispersion of 12.696 .

From the perspective of Chinese-language level, the proportion of learners with a primary Chinese level is the highest, reaching $76.3 \%$. The percentage of learners with an intermediate level is $23.7 \%$. There are no advanced-level learners among the respondents. The author learned from the teachers and students of the Confucius Institute that in normal cases, the students will choose to stop Chinese-language study when they reach the high level because they feel that basic communication with Chinese people is no longer a problem for them, and that if they have passed the HSK5 exam, their motivation for learning will be relatively weakened. Secondly, the class with the highest level in the Confucius Institute at the Eotvos Lorand University is modul32, and the students have learned Chinese for six years. According to the class teacher, a few students can be regarded as advanced learners. But when they filled in the questionnaire, they still classified themselves into the intermediate-level learners.

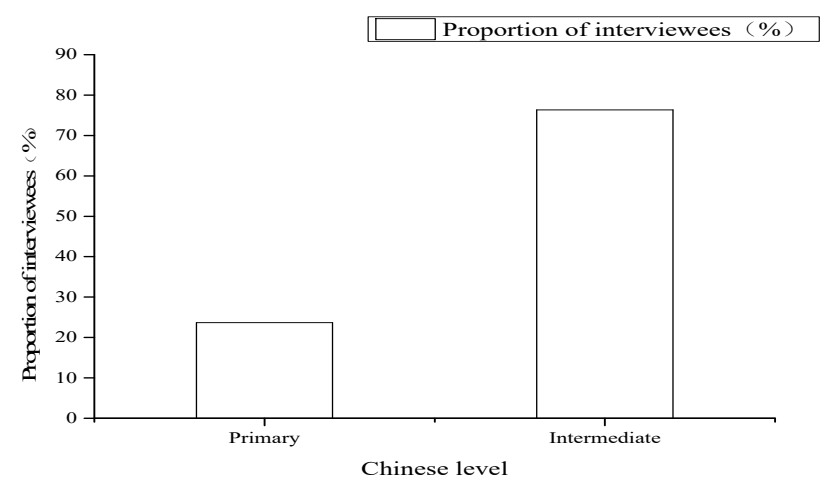

Figure. 1. The respondents' Chinese proficiency chart

In terms of profession, the proportion of students is the highest, followed by professionals or technical staff (including teachers, lawyers, doctors, etc.) and company staff, as well as a small number of civil servants and administrators. After the cross-analysis of career and age, it was found that the occupational results were also consistent with the age. The average age of Chinese-language learners in the Confucius institute is 32 years old, while the proportion of students is the highest. The author learned from the return visit that the Confucius Institute has a number of learners who are about 30 years of age who will continue to pursue master's degree in other fields after completing their studies and graduation, thus enhancing their future professional competitiveness. 
Table 1. The occupational composition of students at the Confucius Institute of the Eotvos Lorand University

\begin{tabular}{cccccc}
\hline & & Frequency & Percentage & Valid Percent & Cumulative percentage \\
\hline \multirow{2}{*}{ Effective } & Students & 28 & 30.1 & 30.1 & 30.1 \\
\hline & Businessman & 3 & 3.2 & 3.2 & 33.3 \\
\hline Office clerk & 17 & 18.3 & 18.3 & 51.6 \\
\hline Technicist & 20 & 21.5 & 21.5 & 73.1 \\
\hline Civil servant & 10 & 10.8 & 10.8 & 93.9 \\
\hline Managers & 7 & 7.5 & 7.5 & 92.5 \\
\hline Workers & 1 & 1.1 & 1.1 & 94.5 \\
\hline Freelance & 2 & 2.2 & 2.2 & 95.7 \\
\hline Unemployed & 1 & 1.1 & 1.1 & 100.0 \\
\hline Others & 4 & 4.3 & 4.3 & \\
\hline Total & 93 & 100.0 & 100.0 & \\
\hline
\end{tabular}

From the perspective of educational background, secondary school education accounted for 31.2\%; undergraduate education accounted for $34.4 \%$; master's degree accounted for $28 \%$; and doctoral degree accounted for $6 \%$. It can be seen from the figure that the proportion of university education is the highest, followed by secondary school education, and the proportion of graduate education is also very high. overall, the educational level of the Chinese-language learners in the Confucius Institute of the Eotvos Lorand University is high.

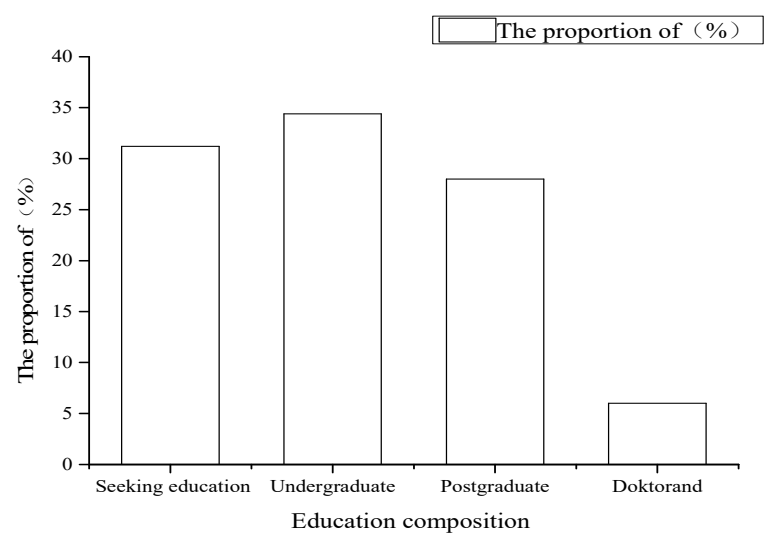

Figure. 2. The composition of Chinese learners' educational background in the Confucius Institute at the Eotvos Lorand University

\subsection{Language-Learning Attitude Analysis of the Respondents}

According to the data, $45.2 \%$ of the respondents say it is difficult to learn Chinese; $31.2 \%$ of the respondents think Chinese is more difficult than other languages; $20.4 \%$ of the respondents think Chinese is not too difficult, and 3.2\% think Chinese is not difficult at all. Chinese-language learners' fear of Chinese language will affect their enthusiasm for learning Chinese to a certain extent. It is believed that the harder Chinese language is, the more vulnerable it is to encounter frustration in learning Chinese. 


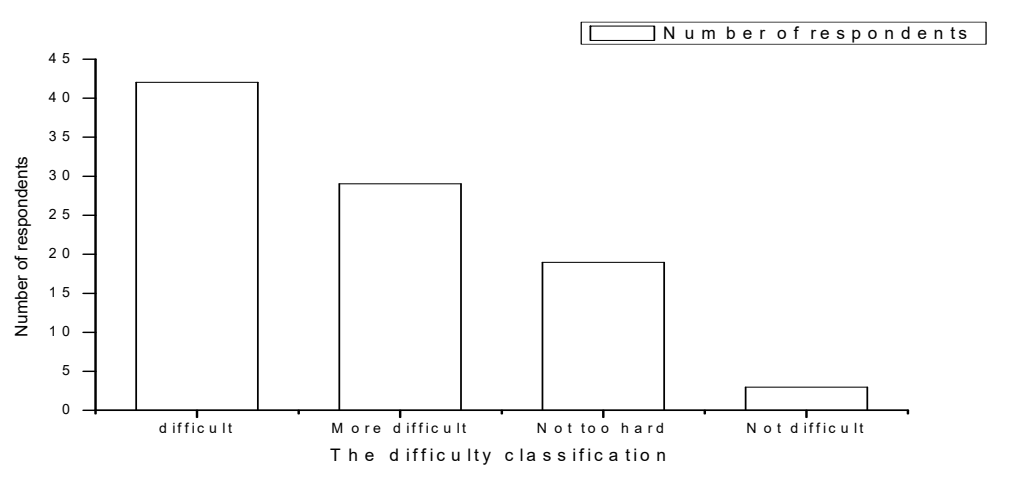

Figure. 3. The respondents' cognition of Chinese-language's difficulty

\subsection{Analysis of Respondents' Cognition and Attitudes Towards Chinese Culture}

In order to investigate the Chinese learners' knowledge and understanding of Chinese culture of the Confucius Institute at the Eotvos Lorand University, the topics on the Chinese capital, traditional Chinese festivals, and famous Chinese figures were designed. The survey results are as follows: regarding the topic "Capital of China", none of the respondents gave wrong answers. In the question "How many festivals do you know in China?", it is clear that the answer with the highest frequency is the Spring Festival, with 86 occurrences, followed by 38 occurrences of the Lantern Festivals, 34 occurrences of the Dragon Boat Festival, and 37 occurrences of the Mid-Autumn Festival. Ching Ming Festival is the lowest-recognized festival, with only 26 occurrences in the answer sheet. In the question "Do you know the following Chinese persons?", the top three answers are Confucius, Jackie Chan, and Mao Zedong. The most well-known Chinese to the Hungarians is Confucius, with the highest selected rate of $95.7 \%$, followed by Jackie Chan and Mao Zedong, accounting for 94.6\%. In the question "Do you like China in general?", $50.5 \%$ of the respondents gave the positive answer, and up to $38.7 \%$ of the respondents say they like China very much. Only one person says he doesn't like China at all. The author paid a return visit to the Hungarian who chose "disliked China very much". The respondent mentioned more sensitive political issues because he had a disagreement with the Chinese government on the issue of Taiwan and he felt that China was too sensitive to political problems. $7.5 \%$ of the respondents gave indefinite answers, and two respondents did not answer this question.

From the survey of Hungarians' attitudes toward Chinese culture and Chinese people, it can be seen that the attitudes of the respondents to Chinese culture and China tend to be positive. So where do the respondents receive Chinese culture? As shown in the figure below, the highest proportion is the Chinese class in the Confucius Institute. It indicates that the Chinese class is still an important channel for the interviewees to contact with Chinese culture. Therefore, it is more important to optimize the Chinese course and strengthen the training of Chinese teachers.

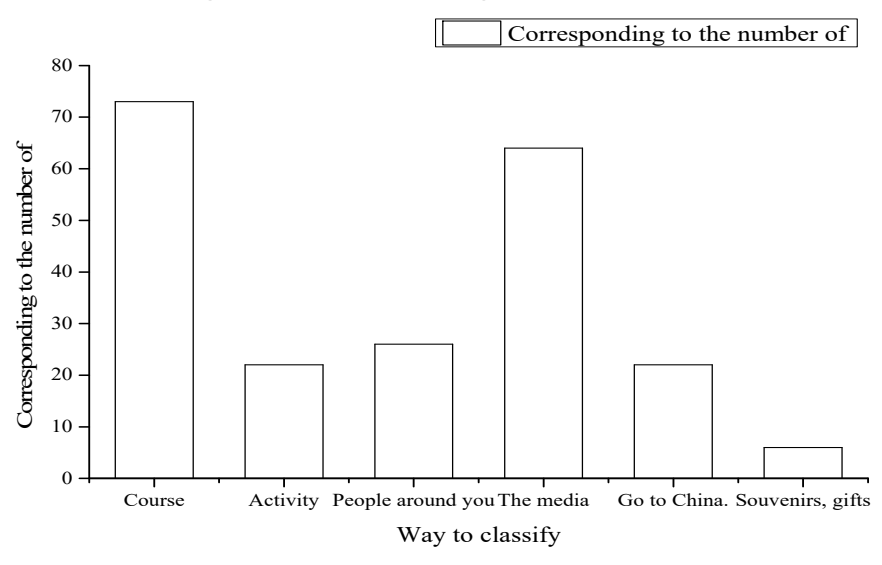

Figure. 4.Respondents' ways of accepting Chinese culture 


\section{Conclusion}

Due to the historical and cultural origins of Hungary and China, Hungary has a lot in common with China culturally. From the survey results, it can also be seen that the learners of the Confucius Institute at the Eotvos Lorand University, Hungary, are generally having a positive attitude towards China and have higher levels of acceptance of the three aspects of Chinese culture mentioned above on the whole. However, there is still room for development in terms of the management mechanism, the construction of teachers from the perspective of the Confucius Institute itself, and the content and mode of the dissemination of the Confucius Institute. The author took the Confucius Institute at the Eotvos Lorand University, Hungary, as an example and he considered the spread of Chinese culture in Hungary and put forward corresponding suggestions based on the results of this investigation.

\section{References}

[1] Balmer J M T, Chen W. China's brands, China's brand development strategies and corporate brand communications in China [J]. Journal of Brand Management, 2015, 22(3): 175-193.

[2] Liu Y. 8. Factor Analysis and Countermeasures of International Popularization of Martial Arts with the Help of Confucius Institutes [J]. Revista de la Facultad de Ingeniería, 2017, 32(11).

[3] Koch P T, Koch B, Menon T, et al. Cultural friction in leadership beliefs and foreign-invested enterprise survival [J]. Journal of International Business Studies, 2016, 47(4): 453-470.

[4] Stambach A. Confucius Institute programming in the United States: Language ideology, hegemony, and the making of Chinese culture in university classes [J]. Anthropology \& Education Quarterly, 2015, 46(1): 55-70.

[5] Xu C, Yao F, Zhang F. An Investigation of Confucius Institute's Effects on China's OFDI via Cultural Difference and Institutional Quality $[\mathrm{M}] / /$ College of Business and Economics, University of West Virginia Working paper. 2015: 15-45.

[6] Barkema H G, Chen X P, George G, et al. West meets East: New concepts and theories [J]. Academy of Management Journal, 2015, 58(2): 460.

[7] Sundiman D, Idrus M S. Confucianism ethic, Guanxi, and acculturation role on the knowledge transfer process of Chinese descendant in Indonesia [J]. International Journal of Knowledge Management Studies, 2015, 6(3): 261-278

[8] Xie N. "It Depends" on power: A case study of China's Confucius Institute as public relations function abroad [J]. China Media Research, 2017, 13(3): 99-109. 